\title{
PENJADWALAN PENGIRIMAN PRODUK KAOS OLEH C.V. CHRONICLE MART KEPADA SUB DISTRIBUTOR CIANJUR DENGAN MENGUNAKAN METODA DRP (DISTRIBUTION REQUIREMENT PLANNING)
}

\author{
Akhmad Sutoni, Dimas Agustian ${ }^{2}$ \\ E-mail: tbungsu13@gmail.com \\ Teknik Industri Universitas Suryakancana,Cianjur,Indonesia \\ DOI Number : $\underline{10.30988 / \text { imil.v1i2.24 }}$
}

\begin{abstract}
Pattern of market demand for company C.V. Chronicle Mart in each period is not constant, always changing. The Company also faces competition with companies engaged in similar fields in order to meet market demand. Production planning activities are the company's strategy in conducting its production process to face the changing market demand. The company has problems with the quantity of goods production and distribution system that compete well, such as delivery time, quantity, and type of goods delivered, resulting in shortage or excess inventory. Method for planning and scheduling of distribution activity is by using DRP (Distribution Requirement Planning) with order policy using EOQ (Economic Order Quantity). In this research, we get the optimum cost of 103,265,000 rupiah in a year
\end{abstract}

Keywords: DRP (Distribution Requirement Planning), EOQ (Economic Order Quantity), Inventory System.

\begin{abstract}
Abstrak
Pola permintaan pasar untuk perusahaan C.V. Chronicle Mart dalam setiap periodenya bersifat tidak konstan, selalu berubah-ubah. Perusahaan juga menghadapi persaingan dengan perusahaan yang bergerak dalam bidang sejenis dalam rangka memenuhi permintaan pasar. Kegiatan perencanaan produksi merupakan strategi perusahaan dalam melakukan proses produksinya menghadapi demand pasar yang berubah-ubah. Perusahaan ini mempunyai masalah pada jumlah produksi barang dan sistem distribusi yang kurang baik, seperti waktu pengiriman, jumlah, dan jenis barang yang dikirimkan, sehingga mengakibatkan terjadinya kekurangan atau kelebihan persediaan. Metode untuk perencanaan dan penjadwalan aktivitas distribusi adalah dengan menggunakan DRP (Distribution Requirement Planning) dengan kebijakan order menggunakan EOQ (Economic Order Quantity). Dalam penelitian ini didapat total biaya yang optimum sebesar 103.265 .000 rupiah dalam setahun
\end{abstract}

Kata kunci: DRP (Distribution Requirement Planning), EOQ (Economic Order Quantity), Sistem Persediaan. 


\section{PENDAHULUAN}

\subsection{Latar Belakang Masalah}

C.V. Chronicle Mart adalah sebuah perusahaan kecil yang menjual produk pakaian berupa kaos. Seiring berjalannya waktu permintaan pasar terhadap produk perusahaan semakin meningkat dan bervariasi. Walaupun beberapa bulan terakhir ada sedikit indikasi penurunan.

Yang menjadi permasalahan adalah pola permintaan dari pasar dalam setiap periodenya sifatnya tidak konstan, selalu berubah-ubah. Selain itu perusahaan juga menghadapi persaingan dengan perusahaan yang bergerak dalam bidang sejenis dalam rangka memenuhi permintaan pasar. Permasalahn ini terjadi ketika perusahaan merasa tidak efektif dan efisien dalam pendistribusian barang. Hal ini dirasakan adanya sesuatu yang tidak baik dalam proses pendistribusian yang dilakukan oleh C.V. Chronicle Mart sebagai subdistributor. Hal ini terjadi karena perencanaan kebutuhan distribusi tidak baik. Untuk melakukan perencanaan kebutuhan distribusi yang baik maka pihak manajemen harus mengelola hal ini dengan baik. Dalam hal ini manajemen produksi berperan penting dalam menyusun suatu perencanaan dan pengenbalian produksi agar perusahaan dapat unggul dalam persaingan pasar. Perusahaan dapat memenuhi permintaan pasar dengan pelayanan terbaik dengan biaya yang seminimum mungkin.

\subsection{Tujuan Penelitian}

Menentukan jumlah pesanan agar tidak terjadi penumpukan barang atau pun adanya lost sale, dengan biaya yang optimum.

\subsection{Supply chain Management (SCM)}

Supply chain pada hakikatnya merupakan jaringan organisasi yang menyangkut hubungan ke hulu (upstream) dan ke hilir (downstream) dalam proses dan kegiatan berbeda yang menghasilkan nilai yang terwujud dalam barang dan jasa ditangan pelanggan terakhir. Perusahan perlu mengelola supply chain-nya dengan baik untuk menciptakan keunggulan kompetitif yang unik pada sistem bisnis (Heizer \& Render, 2001).

Penentu supply chain bukan lagi perusahaan melainkan konsumen (Mattsson, 2003). Konsumen bebas menentukan pilihan mereka pada berbagai pilihan barang atau jasa yang tersedia di pasaran sehingga perusahaan berusaha untuk menyesuaikan produk mereka sesuai pilihan serta kehendak konsumen (Larsen \& Bagchi, 2002, Barrat, 2004).

Menurut Stevenson (2002), ada dua jenis pergerakan (movement) dalam sistem supply chain. Pertama, physical movement of materials yaitu pergerakan arus barang dimana umumnya memiliki arah menuju rantai akhir (konsumen), meskipun tidak semua rantai berawal dengan bahan baku. Kedua exchange of information yaitu pergerakan arus informasi ini menuju dua arah, baik menju rantai awal maupun rantai akhir, disepanjang supply chain.

\subsection{Distribusi}

Pengertian kegiatan distribusi adalah suatu aktivitas perpindahan barang dan jaa dari sumbernya ke pelanggan atau konsumen akhir mellui jalur distribusi secaratepat waktu (Assauri : 2004)

Definisi kegiatan distribusi adalah suatu kegiatan penyaluran atau pengiriman produk agar sampai ke tangan konsumen akhir (Soekartawi : 2001).

Lembaga-lembaga yang berperan dalam kegiatan distribusi ini adalah produsen, perantara (agen atau pedagang) dan konsumen atau pemakai industri (Basu Swastha : 2002).

Menurut Alma (2007, p49), saluran distribusi merupakan lembaga yang saling terkait untuk menjadi produk atau jasa siap digunakan atau dikonsumsi. 
Menurut Tjiptono (2008, p285), saluran distribusi dapat diartikan sebagai kegiatan pemasaran yang berusaha memperlancar dan mempermudah penyampaian barang dan jasa dari produsen kekonsumen, sehingga penggunaannya sesuai dengan yang diperluas. Menurut Daniel (2003, p8), saluran distribusi adalah serangkaian dari organisasi yang saling bergantung yang memudahkan pemindahan kepemilikan sebagaimana produk-produk bergerak dari produsen ke pengguna atau pelanggan.

Sedangkan menurut Kotler (2010, p106) saluran pemasaran adalah sekelompok orgnaisasi yang saling begantung dan terlibat dalam proses pembuatan produk atau jasa yang disediakan untuk digunakan atau dikonsumsi.

Adapun hal-hal yang perlu diperhatikan dalam saluran distribusi antara lain:

Saluran, cangkupan, jenis, lokasi, sediaan, transportasi, dan logistik. (kotler, 1995)

Distribution Requirements Planning berfungsi menentukan kebutuhan-kebutuhan untuk mengisi kembali inventori pada branch warehouse (synonym: distribution center). Sedangkan distribution resource planning merupakan perluasan dari Distribution Requirements Planning yang mencakup lebih dari sekedar sistem perencanaan dan pengendalian dari sumber-sumber yang terkait dalam sistem distribusi seperti: warehouse space, tenaga kerja, uang fasilitas, fasilitas transfortasi, dan warehousing. Termasuk di sini adalah keterkaitan dari replenishment system ke financial system dan penggunaan simulasi sebagai alat untuk meningkatkan performansi system. (Gaspersz, 1998 : 300).

Distribution Requirement planning merupakan aplikasi dari angka logika Material Requirement Planning (MRP). Persediaan Bill of Material (BOM) pada MRP diganti dengan Bill of Distribution (BOD) pada Distribution Requirement Planning (DRP) menggunakan logika Time Phased On Point (TPOP) untuk memerlukan pengadaan kebutuhan pada jaringan (Richard J. Tersine, Principle Inventory and Material Management, 1998).

\subsection{Peramalan}

Peramalan atau Forecasting adalah suatu perkiraan tingkat permintaan yang diharapkan untuk suatu produk atau beberapa produk dalam periode waktu tertentu dimasa yang akan datang (Gaspersz, 1998).

Menurut Lindawati (2003), dalam sistem peramalan, penggunaan model peramalan akan memberikan nilai ramalan yang berbeda dan derajat dari forecast error yang berbeda pula. Salah satu seni dalam melakukan peramalan adalah memilih model peramalan terbaik yang mampu mengidentifikasikan dan menanggapi pola aktivitas historis dari data. Secara umum, model peramalan dapat dikelompokkan ke dalam 2 kelompok utama, yaitu metode kualitatif dan metode kuantitatif.

Pada penelitian ini menggunakan Metode Peramalan Kuantitatif, yaitu metode peramalan Regresi Linier berdasarkan Plot data penjualan masa lalu.

Berikut merupakan rumus dari metode Peramaln Linier :

Mencari a

Rumus :

$$
\begin{aligned}
& \mathrm{a}=\left(\left(\sum \mathrm{Xt} * \sum \mathrm{t}^{\wedge} 2\right)-\left(\sum \mathrm{t} * \sum \mathrm{Xt} \cdot \mathrm{t}\right)\right) /((\mathrm{t} * \\
& \left.\left.\sum \mathrm{t}^{\wedge} 2\right)-\llbracket\left(\sum \mathrm{t}\right) \rrbracket \wedge 2\right)
\end{aligned}
$$

Mencari b

Rumus :

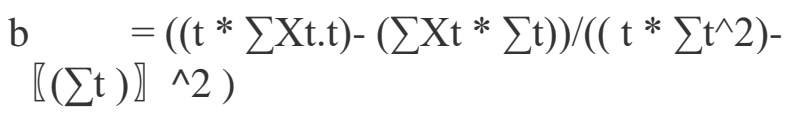

\section{Mencari Ft}

Rumus :

$\mathrm{Ft}=\mathrm{a}+\mathrm{b} . \mathrm{t}$

Mencari et

et $=$ Error (kesalahan perhitungan peramalan)

Rumus :

et $=$ Demand - Peramalan

et $=\mathrm{Xt}-\mathrm{Ft}$ 


\subsection{Persediaan}

Persediaan merupakan sejumlah bahan-bahan, bagian-bagian yang disediakan dan bahanbahan dalam proses yang terdapat dalam perusahaan untuk proses produksi, serta barang-barang jadi atau produk yang disediakan untuk memenuhi permintaan dari konsuman dalam setiap waktu (Rangkuti, 2002 :2)

Selain itu menurut Biegel persediaan adalah bahan yang disimpan dalam gudang untuk kemudian digunakan atau dijual. Persediaan bahan baku harus diadakan karena secara umum adalah tidak ekonomis apabila membeli atau menjadwalkan penyerahan bahan baku saat diperlukan dalam proses pembuatan (Biegel,1992 : 112).

Persediaan dapat dikatakan sebagai sumberdaya yang menganggur, yang menunggu proses lebih lanjut. Persediaan dapat berupa bahan baku, bahan setengah jadi (WIP), produk jadi, peralatan dan lain-lain (Tersine, $1988: 3$ ).

Beberapa kerugian yang akan diderita perusahaan apabila penyelenggaraan persediaan bahan baku yang terlalu besar adalah sebagai berikut :

1. Biaya penyimpanan atau pergudangan yang akan menjadi tanggungan perusahaan yang bersangkutan.

2. Perusahaan harus menyediakan dana yang cukup besar untuk mengadakan pembelian bahan.

3. Tingginya biaya penyimpanan yang ada dalam perusahaan tersebut serta investasi dalam persediaan bahan baku dari perusahaan akan mengakibatkan berkurangnya dana pembiayaan dan investasi dalam bidang lain.

4. Bahan baku yang disimpan seringkali berubah baik secara kimia, sehingga tidak dapat digunakan lagi.

5. Penurunan harga pasar akan merupakan suatu kerugian tidak sedikit di dalam perusahaan. (Tersine, $1988: 3$ ).

\subsection{Metode Economic Order Quantity}

(Dasar-dasar Manajemen Produksi dan Operasi, T. Hani Handoko, 2011:340)

Penetapan ukuran lot dengan metode ini tidak pernah dilupakan dalam lingkungan rencana kebutuhan bahan baku, karena metoda ini sangat popular dalam sistem persediaan tradisional.

Adapun langkah-langkah perhitungan pengolahan data Economic Order Quantity adalah sebagai berikut :

a.Mencari demand rata-rata

$$
\bar{D}_{t}=\frac{\sum D_{t}}{T}
$$

b.Hitung penentuan lot :

Dimana :

$$
E O Q=\sqrt{\frac{2 \overline{D_{t}} s}{h}}
$$

$$
\begin{aligned}
& \bar{D}_{t}=\text { kebutuhan rata-rata per periode } \\
& \mathrm{S}=\text { ongkos pesan persekali pesan } \\
& \mathrm{H}=\text { ongkos simpan per periode }
\end{aligned}
$$

c. Pengambilan keputusan dalam menentukan besarnya ukuran lot dan waktu pemesanan d. Hitung ongkos total.

Ongkos Total $=$ Jumlah Biaya Pesan + Jumlah Biaya Simpan

\section{METODE}

Metoda yang digunakan dengan menggunakan DRP (Distribution Requirment Planning), dengan kebijakan EOQ (Economic Order Quantity). Adapun langkah-langkah pemecahan masalahnya sebagai berikut : identifikasi masalah, pengumpulan data, peramalan, perhitugan EOQ, perhitungan DRP, analisis, kesimpulan.

\section{HASIL DAN PEMBAHASAN}

Di bawah ini (Tabel 1) adalah data permintaan kaos (15 jenis kaos) selama satu tahun. Jumlah ini di dapat dari hasil penjualan data masa lalu (November 2015 - Oktober 2016) di C.V. Chronicle Mart. 
Tabel 1. Data Permintaan dari Bulan November 2015 - Oktober 2016

\begin{tabular}{|c|c|c|c|c|c|c|c|c|c|c|c|c|c|c|c|}
\hline \multirow{2}{*}{ No } & \multirow{2}{*}{ Nama Produk } & \multicolumn{13}{|c|}{ Demand } & \multirow[b]{2}{*}{ Total } \\
\hline & & November & Desember & Januari & Februa & Mare & & Lpril & Mei & Juni & Juli & Agustus & September & Oktober & \\
\hline 1 & Puth $, 0,305$ & 21 & 18 & 3 & 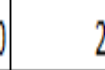 & & 30 & 24 & 30 & 24 & 30 & 18 & 30 & 12 & 294 \\
\hline 2 & Hitam, 0,30s & 30 & 30 & 2 & 2 & 4 & 30 & 21 & 21 & 30 & 24 & 21 & 30 & 12 & 294 \\
\hline 3 & Biru d, $0,30 \mathrm{~s}$ & 21 & 24 & 2 & 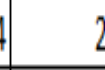 & & 12 & 21 & 12 & 30 & 12 & 30 & 24 & 30 & 261 \\
\hline 4 & Ping, $V_{1}, 305$ & 27 & 21 & 1 & 2 & 1 & 11 & 21 & 21 & 24 & 21 & 18 & 24 & 18 & 249 \\
\hline 5 & Birud, $0,20 \mathrm{~s}$ & 21 & 21 & 2 & 2 & 1 & 11 & 21 & 6 & 21 & 21 & 21 & 21 & 21 & 237 \\
\hline 6 & Birud, V, 2OS & 21 & 21 & 2 & 2 & 1 & 11 & 21 & 6 & 21 & 21 & 21 & 21 & 21 & 237 \\
\hline 7 & Hitam, 0,20s & 21 & 21 & 1 & 2 & 1 & 11 & 12 & 12 & 21 & 18 & 21 & 21 & 21 & 228 \\
\hline 8 & Putih, $0,20 \mathrm{~s}$ & 18 & 18 & 2 & 4 & & 8 & 21 & 18 & 18 & 18 & 18 & 18 & 12 & 219 \\
\hline 9 & Merahc, 0,305 & 18 & 18 & 1 & 2 & & 8 & 18 & 18 & 18 & 18 & 18 & 18 & 18 & 219 \\
\hline 10 & Merahc, 0,205 & 18 & 18 & 1 & 8 & & 8 & 15 & 18 & 21 & 18 & 21 & 18 & 15 & 216 \\
\hline 11 & Ping, $V_{1} 205$ & 18 & 18 & 1 & 8 & & 8 & 18 & 18 & 18 & 18 & 18 & 18 & 18 & 216 \\
\hline 12 & Merah a, 0,30s & 18 & 18 & 1 & 1 & & 8 & 18 & 18 & 18 & 18 & 18 & 18 & 18 & 216 \\
\hline 13 & Birud, V, 30s & 12 & 21 & 2 & 4 & & 12 & 18 & 12 & 30 & 6 & 30 & 6 & 30 & 213 \\
\hline 14 & Merah $c, 0$, pold & 15 & 15 & 1 & 1 & & 15 & 15 & 15 & 15 & 15 & 15 & 15 & 15 & 180 \\
\hline 15 & Abum t, 0, 30s & 15 & 15 & 1 & 1 & & 15 & 15 & 15 & 15 & 15 & 15 & 15 & 15 & 180 \\
\hline & Total & 294 & 297 & 29 & 29 & 28 & & 279 & 240 & 324 & 273 & 303 & 297 & 276 & 3459 \\
\hline
\end{tabular}

Sumber : C.V. Chronicle Mart 
Dengan melihat plot data masa lalu, maka di bawah ini hasil peramalan dua belas periode ke depn (November 2016 - Oktober 2017) dengan metode Peramalan Regresi Linier.

Berikut merupakan contoh perhitungan dari peramalan Pada metode Peramaln Linier untuk peramalan periode ke-1 dan ke-2:

1. Mencari $\alpha$

Rumus :

$\alpha=\frac{\left(\sum X t * \sum t^{2}\right)-\left(\sum t * \sum X t . t\right)}{\left(t * \sum t^{2}\right)-\left(\sum t\right)^{2}}=$

$(3460 * 650)-(78 * 3511,11)$

$$
=\frac{(12 * 650)-6084}{7800-6084}=\frac{1975133,4}{1716}=292,61
$$

2. Mencari $b$

Rumus :

$$
\begin{aligned}
b & =\frac{\left(t * \sum X t . t\right)-\left(\sum X t * \sum t\right)}{\left(t * \sum t^{2}\right)-\left(\sum t\right)^{2}}= \\
\frac{(12 * 3511,27)-(3460 * 78)}{(12 * 650)-6084} & \\
& =\frac{42135,24-269880}{7800-6084}=\frac{-227744,76}{1716}=-0,66
\end{aligned}
$$

3. Mencari Ft

Rumus :

$$
\mathrm{Ft}=\alpha+b . t
$$

$F_{3}=2952,61+(-0,66 * 1)=285$

$F_{8}=2952,61+(0,66 * 2)=284$

Hasil peramalan selengkapnya dua belas periode ke depan bisa dilihat dalam tabel 2 di bawah ini.

Tabel 2. Hasil Peramalan dengan metoda Peramalan Regresi Linier

\begin{tabular}{|c|c|}
\hline Periode & $\begin{array}{c}\text { Hasil } \\
\text { Peramalan } \\
\text { (pcs) }\end{array}$ \\
\hline 1 & 285 \\
\hline 2 & 284 \\
\hline 3 & 283 \\
\hline 4 & 283 \\
\hline 5 & 282 \\
\hline
\end{tabular}

\begin{tabular}{|c|c|}
\hline 6 & 281 \\
\hline 7 & 281 \\
\hline 8 & 280 \\
\hline 9 & 279 \\
\hline 10 & 279 \\
\hline 11 & 278 \\
\hline 12 & 277 \\
\hline
\end{tabular}

Dengan Error (et) sebesar 19.39

Untuk proporsi peramalan dalam dua belas periode ke depan untuk masing-masing jenis kaosnya, bisa dilihat dalm tabel 3 di halaman berikut ini. 
Tabel 3. Proporsi Peramalan Subdistributor Cianjur

\begin{tabular}{|c|c|c|c|c|c|c|c|c|c|c|c|c|c|c|c|c|}
\hline \multirow{2}{*}{ PEENOOE: } & \multirow{2}{*}{$\begin{array}{l}\text { FORCAST } \\
\text { DENAND }\end{array}$} & \multirow{2}{*}{$\begin{array}{c}\text { Puthlo, } 0,306 \\
8,5 \% \\
\end{array}$} & \multicolumn{2}{|c|}{ 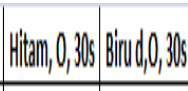 } & \multirow{2}{*}{ 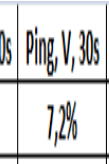 } & \multirow{2}{*}{$\frac{\text { Bind d, O, 20s }}{6,0 \%}$} & \multirow{2}{*}{ 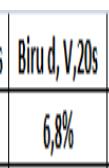 } & \multirow{2}{*}{$\frac{\text { Hitam, }, 0,20 \mathrm{~s}}{6,0 \% \%}$} & \multicolumn{2}{|c|}{ Puthin, O, 2as Merahc, O, 30s } & \multirow{2}{*}{$\frac{\text { Merahc, }, 0,20 s}{6,2 \%}$} & \multirow{2}{*}{$\frac{\operatorname{Ping}_{0}, V_{1}, 20 s}{6,2 \%}$} & \multirow{2}{*}{$\frac{\text { Meralda, } 0,030}{6,20 \%}$} & \multirow{2}{*}{$\frac{\text { Bind d, W, 3Os }}{6,2 \%}$} & Merahc, 0, polo & Abumt, 0,30 \\
\hline & & & $8,5 \%$ & $1,5 \%$ & & & & & $63 \%$ & $6,3 \%$ & & & & & $5,2 \%$ & $5,2 \%$ \\
\hline 1 & 284 & 24,15 & 24,15 & 21,42 & 20,45 & 19,46 & 19,32 & 1872 & 17,98 & 1798 & 17,73 & 1773 & 17,73 & 17,50 & 14,77 & 14,77 \\
\hline 1 & 283 & 2409 & 2409 & 21,37 & 20,41 & 19,4 & 19,27 & 1868 & 17,94 & 17,94 & 17,68 & 17,68 & 17,68 & 17,46 & $1.7,4$ & 14,74 \\
\hline 3 & 283 & 24,03 & $24,0,3$ & 21,32 & 20,36 & 19,37 & 19,13 & 1868 & 17,00 & 17,90 & 17,64 & 17,64 & 17,64 & 17,42 & 19,70 & 1,470 \\
\hline 4 & 282 & 23,98 & 23,98 & 21,27 & 20,31 & 19,32 & 19,18 & 1859 & 1786 & 1786 & 17,00 & 17,70 & 17,00 & 1738 & 14,07 & 14,07 \\
\hline j & 281 & 13,9, & 23,92 & 11,212 & 20,26 & 19,28 & $19,1,4$ & 18,55 & 1781 & 1781 & 17,56 & 17,56 & 1756 & 17,34 & 14,63 & 1468 \\
\hline 6 & 181 & 13,87 & 23,87 & $21,1]$ & 20,22 & 19,13 & 1909 & 1850 & 1777 & 17,77 & 1752 & 17,52 & 1752 & 1730 & 14,00 & 14,60 \\
\hline 1 & 280 & 13,81 & 23,81. & 21.12 & 20,17 & 19,19 & 19,15 & 18,46 & 17,73 & 17,73 & 17,48 & 17,48 & 17,48 & 17,26 & 14,57 & 14,57 \\
\hline 8 & 279 & 13,75 & 23,75 & 21,07 & 20,12 & $19,1,4$ & 19,0 & 18,42 & 1760 & 1760 & 17,4 & 17,4 & 17,4 & 17,11 & 14,53 & 14,53 \\
\hline 9 & 279 & 23,70 & 13,70 & 21,02 & 20,07 & 19,10 & 18966 & 18,37 & 17,65 & 17655 & 17,40 & 17,40 & 17,40 & 17117 & 14,50 & 14,50 \\
\hline 10 & 278 & 23,64 & 23,54 & 20,97 & 20,03 & $19,0,5$ & 189.9 & 1833 & 1761 & 17601 & 17,36 & 17,36 & 1736 & $17,1,3$ & 19,46 & $1,4,46$ \\
\hline 11 & 277 & 125,59 & 23,59 & 20,92 & 1998 & 1901 & 1887 & 18,29 & 17,56 & 17,760 & 17,32 & 17,32 & 17,32 & 17,99 & 14,43 & 10,43 \\
\hline 11 & 277 & 2353 & 23,53 & 20,87 & 1993 & 18,860 & 1882 & 18,24 & 17,52 & 17,52 & 17,27 & 17,27 & $17,17]$ & 17,155 & 19,40 & 16,40 \\
\hline & 3365 & 286,105 & 286,15 & 2537,75 & 24,230 & 230,53 & 228,44 & $221,1,18$ & $213,1,3$ & $213,0,3$ & 210,0 & 20000 & 20000 & 207,31 & 175,00 & 175,00 \\
\hline
\end{tabular}

Sumber : C.V. Chronicle Mart, pengolahan data 
Dalam pengolahan data dengan menggunakan metode EOQ ini menghasilkan total ongkos (jumlah biaya pesan + jumlah biaya simpan) sebesar Rp. 103.265.000 dari keseluruhan jenis produk kaos polos yang berjumlah 15 jenis.

Untuk jumlah order yang ekonomis dan biaya yang dikeluarkan untuk masing-masing jenis produk, selengkapnya bisa dilihat di table 4 (terlampir).

Setelah dilakukan perhitungan EOQ, selanjutnya dibuat perhitungan DRP. Dalam perhitungan DRP diperlukan data-data seperti struktur distribusi perusahaan, data permintaan produk tiap distributor, status persediaan perusahan, serta penentuan ukuran lot.

Data permintaan produk distributor diperoleh dari hasil peramalan. Data permintaan produk ini menjadi input perhitungan DRP pada bagian Gross Requirement. Hasil perhitungan selengkapnya bisa dilihat di table 5, 6, dan 7 (terlampir)

\section{KESIMPULAN}

Untuk merencanakan kebutuhan distribusi, maka harus dibuatkan DRP (Distribution Requirement Planning) yang berfungsi menentukan kebutuhan-kebutuhan untuk mengisi kembali permintaan produk dari hasil permintaan konsumen. Dari hasil perhitungan DRP diketahui total kebutuhan berdasarkan peramalan untuk pland order release untuk setiap tipe. Perencanaan kebutuhan distribusi dengan DRP (Distribution Requirements Planning) yang memakai EOQ (Economic Order Quantity) . akan didapat jumlah pemesanan yang ekonomis, agar tidak terjadi penumpukan barang, atau pun adanya lost sale dan pembengkakan ongkos.

Dari hasil perhitungan DRP dengan kebijakan order EOQ didapat Total Ongkos (Jumlah Biaya
Pesan + Jumlah Biaya Simpan) yang optimum sebesar Rp. 103.265.000.

Dengan jumlah tersebut, hasil ini lebih baik dibanding dengan yang dilakukan perusahaan saat ini.

\section{DAFTAR PUSTAKA}

Alma, Buchari. 2007. Manajemen Pemasaran dan Pemasaran Jasa. Alfabeta. Bandung.

Assauri, Sofjan. 2004. Manajemen Produksi dan Operasi. Fakultas Ekonpmi Universitas Indonesia. Jakarta.

Bagchi,P.K and Larsen, T.S. 2002. Organizational Integration in Supply Chains : A Contingency Approach. Global Journal of Flexible Systems Management. Vol.3 No.1.

Barratt, M. 2004. Understanding the Meaning of Collaboration in the Supply Chain. Supply Chain Management: An International Journal. Vol.9 No.1.

Basu Swastha.2002.Manajemen Pemasaran. Edisi Kedua. Cetakan Kedelapan. Liberty. Jakarta.

Biegel,John E. 1992. Production Control. Prentice Hall of India Private Limited. New Delhi

Gaspersz, Vincent . 1998. Manajemen produktivitas total : strategi peningkatan produktivitas bisnis global. Gramedia. Jakarta.

Handoko, T Hani. 2011. Dasar-dasar Manajemen Produksi dan Operasi. BPFE. Yogyakarta.

Heizer, Jay dan Render Barry. 2008. Manajemen Operasi. Edisi 7. Salemba Empat. Jakarta.

Kotler, Philip and Kevin Lane Keller, 2010. Marketing Management. Edisi 12. Prentice Hall Published. New Jersey. 
Mattsson. 2003. Reorganization of distribution in globalization of markets: the dynamic context of supply chain management. Supply Chain Management: An International Journal, Vol. 8 Issue: 5.

Rangkuty, Freddy, 2004. Manajemen Persediaan.Edisi Dua. Cetakan Keenam.PT. Raja Grafindo Persada. Jakarta.

Richard J. Tersine. 1998. Principle Inventory and Material Management.Soekartawi. 2001. Pengantar agroindustry. Raja Grafindo Persada. Jakarta.

Tjiptono, Fandy. 2008. Strategi Pemasaran. Andi. Yogyakarta. 


\section{LAMPIRAN}

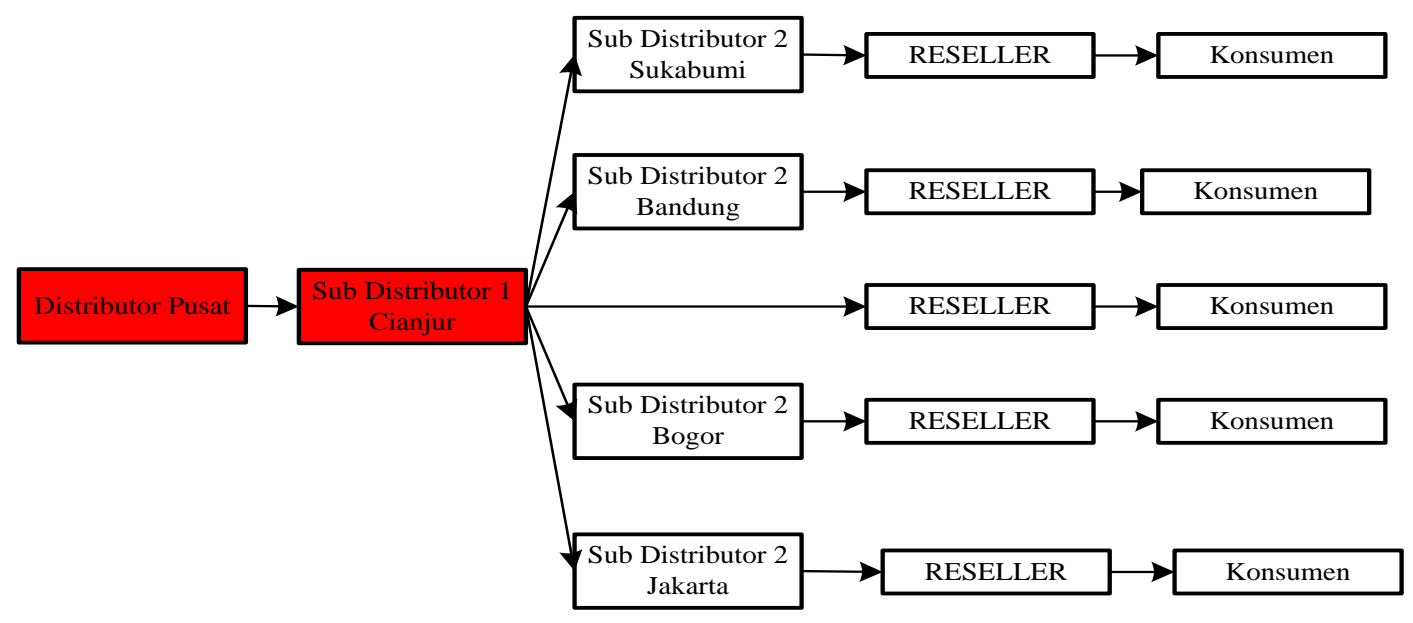

Gambar 1. Struktur Distribusi Perusahaan

Chronicle Mart subdistributor Cianjur (Sub Distributor 1 Cianjur)

( Sumber : C.V. Chronicle Mart )

Tabel 4. Perhitungn EOQ dan Total Ongkos

\begin{tabular}{|c|c|c|c|c|c|c|c|c|c|c|c|c|c|c|}
\hline \multirow{2}{*}{ no. } & \multirow{2}{*}{ Nama Komponen } & \multicolumn{12}{|c|}{ Demand Setiap Bulan } & \multirow{2}{*}{$\begin{array}{r}\text { E Dem } \\
\text { (Uni }\end{array}$} \\
\hline & & 1 & 2 & 3 & 4 & 5 & 6 & 7 & 8 & 9 & 10 & 11 & 12 & \\
\hline 1 & Putih, 0,30 s & 25 & 25 & 25 & 25 & 24 & 24 & 24 & 24 & 24 & 24 & 24 & 24 & 292 \\
\hline 2 & Hitam, $0,30 \mathrm{~s}$ & 25 & 25 & 25 & 25 & 24 & 24 & 24 & 24 & 24 & 24 & 24 & 24 & 292 \\
\hline 3 & Biru d, $0,30 \mathrm{~s}$ & 22 & 22 & 22 & 22 & 22 & 22 & 22 & 22 & 22 & 22 & 21 & 21 & 262 \\
\hline 4 & Ping, $V, 30 \mathrm{~s}$ & 21 & 21 & 21 & 21 & 21 & 21 & 21 & 21 & 21 & 21 & 21 & 20 & 251 \\
\hline 5 & Biru d, 0,20 s & 20 & 20 & 20 & 20 & 20 & 20 & 20 & 20 & 20 & 20 & 20 & 19 & 239 \\
\hline 6 & Biru d, V,20s & 20 & 20 & 20 & 20 & 20 & 20 & 20 & 20 & 19 & 19 & 19 & 19 & 236 \\
\hline 7 & Hitam, $0,20 \mathrm{~s}$ & 19 & 19 & 19 & 19 & 19 & 19 & 19 & 19 & 19 & 19 & 19 & 19 & 228 \\
\hline 8 & Putih, $0,20 \mathrm{~s}$ & 19 & 18 & 18 & 18 & 18 & 18 & 18 & 18 & 18 & 18 & 18 & 18 & 217 \\
\hline 9 & Merah c, $0,30 \mathrm{~s}$ & 19 & 18 & 18 & 18 & 18 & 18 & 18 & 18 & 18 & 18 & 18 & 18 & 217 \\
\hline 10 & Merah c, O, 20s & 18 & 18 & 18 & 18 & 18 & 18 & 18 & 18 & 18 & 18 & 18 & 18 & 216 \\
\hline 11 & Ping, $V, 20$ s & 18 & 18 & 18 & 18 & 18 & 18 & 18 & 18 & 18 & 18 & 18 & 18 & 216 \\
\hline 12 & Merah a, O, 30s & 18 & 18 & 18 & 18 & 18 & 18 & 18 & 18 & 18 & 18 & 18 & 18 & 216 \\
\hline 13 & Biru d, $\mathrm{V}, 30 \mathrm{~s}$ & 18 & 18 & 18 & 18 & 18 & 18 & 18 & 18 & 18 & 18 & 18 & 18 & 216 \\
\hline 14 & Merah c, o, polo & 15 & 15 & 15 & 15 & 15 & 15 & 15 & 15 & 15 & 15 & 15 & 15 & 180 \\
\hline 15 & Abu mt, $0,30 \mathrm{~s}$ & 15 & 15 & 15 & 15 & 15 & 15 & 15 & 15 & 15 & 15 & 15 & 15 & 180 \\
\hline
\end{tabular}

Tabel 5. DRP untuk masing-masing jenis produk

\begin{tabular}{|c|c|c|c|c|c|c|c|c|c|c|c|c|c|}
\hline Perioda & Past Due & Nov & Des & Jan & Feb & Mart & April & Mei & Juni & Juli & Agus & Sept & Okt \\
\hline Gross Requirement & & 25 & 25 & 25 & 25 & 24 & 24 & 24 & 24 & 24 & 24 & 24 & 24 \\
\hline PAB I & & -25 & -17 & \begin{tabular}{|c|}
-9 \\
\end{tabular} & -1 & 8 & -16 & -7 & 2 & -22 & -13 & -4 & 5 \\
\hline Net Requirement & & 25 & 17 & 9 & 1 & -8 & 16 & 7 & -2 & 22 & 13 & 4 & -5 \\
\hline Planned Order Receipt & & 25 & 17 & 9 & 1 & -8 & 16 & 7 & -2 & 22 & 13 & 4 & -5 \\
\hline Planned Order Released & & 33 & 33 & 33 & 33 & & 33 & 33 & & 33 & 33 & 33 & \\
\hline PAB II & & 8 & 16 & 24 & 32 & 8 & 17 & 26 & 2 & 11 & 20 & 29 & 5 \\
\hline Perioda & Past Due & Nov & Des & Jan & Feb & Mart & April & Mei & Juni & Juli & Agus & ept & Okt \\
\hline Gross Requirement & & 25 & 25 & 25 & 25 & 24 & 24 & 24 & 24 & 24 & 24 & 24 & 24 \\
\hline PAB I & & -25 & -17 & -9 & -1 & 8 & -16 & -7 & 2 & -22 & -13 & -4 & 5 \\
\hline Net Requirement & & 25 & 17 & 9 & 1 & -8 & 16 & 7 & -2 & 22 & 13 & 4 & -5 \\
\hline Planned Order Receipt & & 25 & 17 & 9 & 1 & -8 & 16 & 7 & -2 & 22 & 13 & 4 & -5 \\
\hline Planned Order Released & & 33 & 33 & 33 & 33 & & 33 & 33 & & 33 & 33 & 33 & \\
\hline PAB II & & 8 & 16 & 24 & 32 & 8 & 17 & 26 & 2 & 11 & 20 & 29 & 5 \\
\hline
\end{tabular}

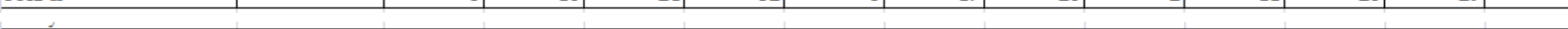

\begin{tabular}{|c|c|c|c|c|c|c|c|c|c|c|c|c|c|}
\hline Perioda & Past Due & Nov & Des & $\operatorname{Jan}$ & $\mathrm{Feb}$ & Mart & April & Mei & Juni & Juli & Agus & Sept & Okt \\
\hline Gross Requirement & & 22 & 22 & 22 & 22 & 22 & 22 & 22 & 22 & 22 & 22 & 21 & 21 \\
\hline PAB I & & -22 & -13 & -4 & 5 & -17 & -13 & -4 & 5 & -17 & -8 & 2 & -19 \\
\hline Net Requirement & & 22 & 13 & 4 & -5 & 17 & 13 & 4 & -5 & 17 & 8 & -2 & 19 \\
\hline Perioda & Past Due & Nov & Des & Jan & $\mathrm{Feb}$ & Mart & April & Mei & Juni & Juli & Agus & Sept & Okt \\
\hline Gross Requirement & & 21 & 21 & 21 & 21 & 21 & 21 & 21 & 21 & 21 & 21 & 21 & 20 \\
\hline PAB I & & -21 & -11 & -1 & 9 & -12 & -2 & 8 & -13 & -3 & 7 & -14 & -3 \\
\hline Net Requirement & & 21 & 11 & 1 & -9 & 12 & 2 & -8 & 13 & 3 & -7 & 14 & 3 \\
\hline Planned Order Receipt & & 21 & 11 & 1 & -9 & 12 & 2 & -8 & 13 & 3 & -7 & 14 & 3 \\
\hline Planned Order Released & & 31 & 31 & 31 & & 31 & 31 & & 31 & 31 & & 31 & 31 \\
\hline PAB II & & 10 & 20 & 30 & 9 & 19 & 29 & 8 & 18 & 28 & 7 & 17 & 28 \\
\hline
\end{tabular}

\begin{tabular}{|c|c|c|c|c|c|c|c|c|c|c|c|c|c|}
\hline Perioda & Past Due & Nov & Des & Jan & $\mathrm{Feb}$ & Mart & April & Mei & Juni & Juli & Agus & Sept & Okt \\
\hline Gross Requirement & & 20 & 20 & 20 & 20 & 20 & 20 & 20 & 20 & 20 & 20 & 20 & 19 \\
\hline PAB I & & -20 & -10 & 0 & -20 & -10 & 0 & -20 & -10 & 0 & -20 & -10 & 1 \\
\hline Net Requirement & & 20 & 10 & 0 & 20 & 10 & 0 & 20 & 10 & 0 & 20 & 10 & -1 \\
\hline
\end{tabular}


Tabel 7. DRP untuk masing-masing jenis produk (Lanjutan)

\begin{tabular}{|c|c|c|c|c|c|c|c|c|c|c|c|c|c|}
\hline Perioda & Past Due & Nov & Des & Jan & Feb & Mart & April & Mei & Juni & Juli & Agus & Sept & Okt \\
\hline Gross Requirement & & 18 & 18 & 18 & 18 & 18 & 18 & 18 & 18 & 18 & 18 & 18 & 18 \\
\hline PAB I & & -18 & -8 & 2 & -16 & -6 & 4 & -14 & -4 & 6 & -12 & -2 & 8 \\
\hline Net Requirement & & 18 & 8 & -2 & 16 & 6 & -4 & 14 & 4 & -6 & 12 & 2 & -8 \\
\hline Planned Order Receipt & & 18 & 8 & -2 & 16 & 6 & -4 & 14 & 4 & -6 & 12 & 2 & -8 \\
\hline Planned Order Released & & 28 & 28 & & 28 & 28 & & 28 & 28 & & 28 & 28 & \\
\hline PAB II & & 10 & 20 & 2 & 12 & 22 & 4 & 14 & 24 & 6 & 16 & 26 & 8 \\
\hline Perioda & Past Due & Nov & Des & Jan & $\mathrm{Feb}$ & Mart & April & Mei & Juni & Juli & Agus & Sept & Okt \\
\hline Gross Requirement & & 18 & 18 & 18 & 18 & 18 & 18 & 18 & 18 & 18 & 18 & 18 & 18 \\
\hline PAB I & & -18 & -8 & 2 & -16 & -6 & 4 & -14 & -4 & 6 & -12 & -2 & 8 \\
\hline Net Requirement & & 18 & 8 & -2 & 16 & 6 & -4 & 14 & 4 & -6 & 12 & 2 & -8 \\
\hline Planned Order Receipt & & 18 & 8 & -2 & 16 & 6 & -4 & 14 & 4 & -6 & 12 & 2 & -8 \\
\hline Planned Order Released & & 28 & 28 & & 28 & 28 & & 28 & 28 & & 28 & 28 & \\
\hline PAB II & & 10 & 20 & 2 & 12 & 22 & 4 & 14 & 24 & 6 & 16 & 26 & 8 \\
\hline & & & & & & & & & & & & & \\
\hline Perioda & Past Due & Nov & \begin{tabular}{|l|l|} 
Des \\
\end{tabular} & Jan & Feb & Mart & April & Mei & Juni & Juli & Agus & Sept & Okt \\
\hline Gross Requirement & & 18 & 18 & 18 & 18 & 18 & 18 & 18 & 18 & 18 & 18 & 18 & 18 \\
\hline PAB I & & -18 & -8 & 2 & -16 & -6 & 4 & -14 & -4 & 6 & -12 & -2 & 8 \\
\hline Net Requirement & & 18 & 8 & -2 & 16 & 6 & -4 & 14 & 4 & -6 & 12 & 2 & -8 \\
\hline Planned Order Receipt & & 18 & 8 & -2 & 16 & 6 & -4 & 14 & 4 & -6 & 12 & 2 & -8 \\
\hline Planned Order Released & & 28 & 28 & & 28 & 28 & & 28 & 28 & & 28 & 28 & \\
\hline PAB II & & 10 & 20 & 2 & 12 & 22 & 4 & 14 & 24 & 6 & 16 & 26 & 8 \\
\hline Perioda & Past Due & Nov & Des & Jan & Feb & Mart & April & Mei & Juni & Juli & Agus & Sept & Okt \\
\hline Gross Requirement & & 15 & 15 & 15 & 15 & 15 & 15 & 15 & 15 & 15 & 15 & 15 & 15 \\
\hline PAB I & & -15 & -4 & 7 & -8 & 3 & -12 & -1 & 10 & -5 & 6 & -9 & 2 \\
\hline Net Requirement & & 15 & 4 & -7 & 8 & -3 & 12 & 1 & -10 & 5 & -6 & 9 & -2 \\
\hline Planned Order Receipt & & 15 & 4 & -7 & 8 & -3 & 12 & 1 & -10 & 5 & -6 & 9 & -2 \\
\hline Planned Order Released & & 26 & 26 & & 26 & & 26 & 26 & & 26 & & 26 & \\
\hline PAB II & & 11 & 22 & 7 & 18 & 3 & 14 & 25 & 10 & 21 & 6 & 17 & 2 \\
\hline Perioda & Past Due & Nov & Des & Jan & $\mathrm{Feb}$ & Mart & April & Mei & Juni & Juli & Agus & Sept & Okt \\
\hline Gross Requirement & & 15 & 15 & 15 & 15 & 15 & 15 & 15 & 15 & 15 & 15 & 15 & 15 \\
\hline PAB I & & -15 & -4 & 7 & -8 & 3 & -12 & -1 & 10 & -5 & 6 & -9 & 2 \\
\hline Net Requirement & & 15 & 4 & -7 & 8 & -3 & 12 & 1 & -10 & 5 & -6 & 9 & -2 \\
\hline Planned Order Receipt & & 15 & 4 & -7 & 8 & -3 & 12 & 1 & -10 & 5 & -6 & 9 & -2 \\
\hline Planned Order Released & & 26 & 26 & & 26 & & 26 & 26 & & 26 & & 26 & \\
\hline PAB II & & 11 & 22 & 7 & 18 & 3 & 14 & 25 & 10 & 21 & 6 & 17 & 2 \\
\hline
\end{tabular}

\begin{tabular}{|c|c|c|c|c|c|c|c|c|c|c|c|c|c|}
\hline Perioda & Past Due & Nov & Des & Jan & Feb & Mart & April & Mei & Juni & Juli & Agus & Sept & Okt \\
\hline Gross Requirement & & 18 & 18 & 18 & 18 & 18 & 18 & 18 & 18 & 18 & 18 & 18 & 18 \\
\hline PAB I & & -18 & -8 & 2 & -16 & -6 & 4 & -14 & -4 & 6 & -12 & -2 & 8 \\
\hline Net Requirement & & 18 & 8 & -2 & 16 & 6 & -4 & 14 & 4 & -6 & 12 & 2 & -8 \\
\hline Planned Order Receipt & & 18 & 8 & -2 & 16 & 6 & -4 & 14 & 4 & -6 & 12 & 2 & -8 \\
\hline Planned Order Released & & 28 & 28 & & 28 & 28 & & 28 & 28 & & 28 & 28 & \\
\hline PAB II & & 10 & 20 & 2 & 12 & 22 & 4 & 14 & 24 & 6 & 16 & 26 & 8 \\
\hline Perioda & Past Due & Nov & Des & Jan & Feb & Mart & April & Mei & Juni & Juli & Agus & Sept & Okt \\
\hline Gross Requirement & & 15 & 15 & 15 & 15 & 15 & 15 & 15 & 15 & 15 & 15 & 15 & 15 \\
\hline PAB I & & -15 & -4 & 7 & -8 & 3 & -12 & -1 & 10 & -5 & 6 & -9 & 2 \\
\hline Net Requirement & & 15 & 4 & -7 & 8 & -3 & 12 & 1 & -10 & 5 & -6 & 9 & -2 \\
\hline Planned Order Receipt & & 15 & 4 & -7 & 8 & -3 & 12 & 1 & -10 & 5 & -6 & 9 & -2 \\
\hline Planned Order Released & & 26 & 26 & & 26 & & 26 & 26 & & 26 & & 26 & \\
\hline PAB II & & 11 & 22 & 7 & 18 & 3 & 14 & 25 & 10 & 21 & 6 & 17 & 2 \\
\hline Perioda & Past Due & Nov & Des & Jan & Feb & Mart & April & Mei & Juni & Juli & Agus & Sept & Okt \\
\hline Gross Requirement & & 15 & 15 & 15 & 15 & 15 & 15 & 15 & 15 & 15 & 15 & 15 & 15 \\
\hline PAB I & & -15 & -4 & 7 & -8 & 3 & -12 & -1 & 10 & -5 & 6 & -9 & 2 \\
\hline Net Requirement & & 15 & 4 & -7 & 8 & -3 & 12 & 1 & -10 & 5 & -6 & 9 & -2 \\
\hline Planned Order Receipt & & 15 & 4 & -7 & 8 & -3 & 12 & 1 & -10 & 5 & -6 & 9 & -2 \\
\hline Planned Order Released & & 26 & 26 & & 26 & & 26 & 26 & & 26 & & 26 & \\
\hline PAB II & & 11 & 22 & 7 & 18 & 3 & 14 & 25 & 10 & 21 & 6 & 17 & 2 \\
\hline
\end{tabular}

